UDC 551.46: 532.59

\title{
WAVE DYNAMICS FEATURES IN A SEA ICE AREA.
}

\author{
A.A. Bukatov, A.E. Bukatov, V.V. Zharkov, D.D. Zav'yalov. \\ Marine Hydrophysical Institute of Ukrainian National Academy of Sciences \\ 2, Kapitanskaja Str., Sevastopol 99011.E-mail: ocean@alpha.mhi.iuf.net
}

\begin{abstract}
On a base of developed hydrodynamic models the reflecting capacities of edges, cracks and ice field breaks are studied when the surface waves pass through them. It was investigated the ice flexural rigidity and compression effects on the spatial distribution of wave disturbance amplitudes and bend stresses of the ice cover on both sides of the examined horizontal non-uniformity. Assessment of the ice breaking possibility within the edge-side zones was made. The surface wave propagation from the basin deep-water area through the bottom's step into the area of the finite depth is investigated. The spatial and temporal features of the formed dynamic frontal zones on both sides of the step are revealed. The dependence of the basin surface displacement amplitudes and wave current velocities on the ice thickness, incident wave periods, and depth of the step occurrence, is studied. The three-dimensional bending vibrations of floating ice cover induced by a moving vortex formation are studied. Dependence of the amplitude-phase vibration characteristics on the ice rigidity in bending, angular velocity and forward speed of the vortex is investigated. Spatial distribution of the flexural-gravity disturbances both in front of the moving pressure region and in the back wake is analyzed. A mathematical model of the non-linear dynamics of surface waves of finite amplitude in the ice floes seas was developed involving the method of multiscale expansions. Using the model, it was studied the dependence of the amplitude-phase structure of disturbances, formed by the propagating non-linear periodic waves, on the basin depth, ice thickness and non-linearity of its vertical acceleration, frequency and steepness of initial wave harmonics. The ice Stokes drift velocity was estimated as well as the ice induced non-linear mass transport analyzed.
\end{abstract}

Key words: Wave propagation, ice effect, load movement, ice deflection, wave disturbances, Stokes' drift.

Особенности волновой динамики в покрывающихся льдом морских акваториях. А.А. Букатов, А.Е. Букатов, В.В. Жарков, Д.Д. Завьялов.

Резюме. На основе разработанных гидродинамических моделей выполнено исследование экранирующих свойств кромок, трещин и разломов ледяных полей при распространении через них поверхностных волн. Изучено влияние цилиндрической жесткости льда и силы ледового сжатия на пространственное распределение амплитуд волновых возмущений и напряжений изгиба ледяного покрова по обе стороны от каждой из рассмотренных горизонтальных неоднородностей. Дана оценка возможности разлома льда в прикромочных зонах. Исследовано распространение поверхностных волн из глубоководной области бассейна через уступ дна в область конечной глубины. Выявлены пространственно-временные особенности структуры формируемых динамических фронтальных зон по обе стороны от уступа. Исследована зависимость амплитуд смещения поверхности бассейна и скорости волновых течений от толщины льда, периода набегающей волны и глубины залегания уступа. Изучены трехмерные изгибные колебания плавающего ледяного покрова, возбуждаемые движущимся вихревым образованием. Исследована зависимость амплитуднофазовых характеристик колебаний от изгибной жесткости льда, угловой и поступательной скоростей вихря. Выполнен анализ пространственного распределения изгибно-гравитационных возмущений впереди движущейся области и в волновом следе за ней. Методом многомасштабных разложений построена математическая модель нелинейной динамики поверхностных волн конечной амплитуды в морских акваториях с плавающим льдом. На ее основе исследована зависимость амплитудно-фазовой структуры возмущений, формируемых бегущими нелинейными периодическими волнами, от глубины бассейна, толщины льда и нелинейности его вертикального ускорения, частоты и крутизны начальных волновых гармоник. Дана оценка скорости стоксового дрейфа льда, проведен анализ влияния льда на нелинейный перенос массы.

\section{Introduction.}

Sea ice plays an important role in the interaction between the ocean and atmosphere and in a great many geophysical processes, being one of the factors forming the climate of our planet. That indicates the importance and actuality of the investigation of the dynamic processes under the ice conditions. Besides, solving the problems of raw and mineral resources mastering and navigation in the high latitudes requires understanding of the ice cover dynamic and hydrodynamic disturbances peculiarities. Some results on the research of the wave processes in ice-covered seas are given here. 


\section{Wave propagation through the ice cover non-uniformities.}

Notwithstanding a lot of the mathematical models describing the wave processes in ice-covered basins, there remains a number of questions, in particular, concerning the influence of the ice compression forces on the wave transmission across the edge and reflection from it; peculiarities of the wave propagation through a crack or a break in the ice field, etc.

Using hydrodynamic models, the screening property of horizontal non-uniformities in the ice fields when the surface waves propagate across them was studied. The horizontal non-uniformities such as edges, cracks, and breaks in the ice were modeled choosing the corresponding boundarycontact conditions (Kheisin, 1967; Krasil'nikov, 1967; Wadhams, 1986; Fox and Squire, 1990).

Effects of the ice flexural rigidity and ice pressing force on the spatial amplitude distribution of the ice bend and fluid disturbances nearby and far from the horizontal non-uniformities were studied (Bukatov and Zav'yalov, 1998). The conditions of ice breaking were investigated and the physical mechanism of the wave disturbances arisen under the ice in the vicinity of breaks was revealed.

It was shown that the coefficient of the wave transmission through the two overlapping ice floes (an ice field break, characterizing by the pin-joint boundary condition) is less sensitive to the basin depth change than to the wave reflection from this non-uniformity. The wave transmission decreases and reflection increases with ice thickness. The ice pressing forces affect not only quantitatively but also qualitatively the distribution of the reflection and transmission amplitude ratios depending on the incident wave period. Increasing of the ice compression results in the shift of the period of maximal (practically full) wave transmission towards its smaller values. The wave period range for which screening capacity of uniformities essentially depends on compressive force was determined.

Assessment of reflection and transmission properties of ice breaks without taking into account damped boundary eigenmodes may lead to essential errors clearly manifested themselves in the reflection coefficient reduction and transmission coefficient overestimation for the incident waves of small and mean periods. The incident waves of the same amplitude but different periods cause the different vertical displacement both close to the line of the floes contact and far from it.

The period at which the ice response is maximal weakly depends on the basin depth and is mainly defined by the ice cover conditions. This period increases with growing ice thickness. For some given amplitude the range of the incident wave periods at which the floes vertical displacement is nearly maximal extends with the basin depth decreasing or the ice thickness increasing. The maximal gradients of the wave parameters of the formed disturbances occur in the vicinity of the floes contact line. The width of this zone depends on the incident waves parameters, basin depth, and ice conditions. For the two touching floes of unequal thickness the reflection coefficient does not practically depend on which side of their contact line the flexural-gravity waves run on.

The dispersion properties of the ice floes free vibrations, which affect the formation of hydrodynamic disturbances in the regions of ice edges, cracks and breaks as well as at the nonuniformities of the basin bottom, are studied (Bukatov and Zav'yalov, 2000). Account for the displacement and rotary inertia of the cross-sections in the equation describing the floating ice cover vibration results in wavelength decreasing of the flexural modes and phase speed restriction of the propagating undamped oscillations of high frequency. Wavelengths of the propagating relaxation oscillations decrease as well. Simultaneously their spatial damping constants decrease. Furthermore attenuation of boundary waves due to the displacement and rotary inertia decreases when they moving away from ice and bottom non-uniformities

\section{Ice effect on wave propagation over a bottom step}

An analysis of the ice floes effect on the propagation of the plane surface waves of a small amplitude from the infinite basin depth through the bottom step to the depth of a finite quantity is carried out (Bukatov and Zharkov, 1998) using the 'wave source' theory (Newman, 1965). The iceinduced changes of the reflected and transmitted waves parameters, water surface disturbances profiles and wave flow velocities depending on the distance to the step were assessed. 
It was shown that the distorting influence of the floating broken ice on the characteristics of the wave disturbances, formed by the surface waves running on the bottom step, occurs mainly at the incident wave frequencies comparable with frequencies of ice buoyancy. The floating broken ice decreases the reflection amplitude coefficient. The frequency of the minimal transmission amplitude coefficient decreases due to the ice. The thicker the ice, the faster reflection and transmission coefficients reach limiting values at the buoyancy frequency. Influence of the ice on the reflection and transmission coefficients becomes weaker with increasing depth of step occurrence.

The frequency of the maximal phase shift of the reflected wave decreases with increasing ice thickness. The ice influence on the frequency of the maximal phase shift of the transmitted wave does not manifest itself. The floating ice diminishes the transmitted wave phase shift at the frequencies exceeding the peak value.

Ice thickness increase results in wavelengths decrease of the basin surface disturbances in front of the step and behind it. Discrepancy between the lengths of wave disturbances before the step and behind it becomes smaller with frequency increasing of an incoming wave. In addition basin surface shape turns to be monochromatic wave one, which is not distorted by the step effect.

The surface disturbance amplitude in front of the step can change as a function of the distance to the step. Ice thickness increase results in decreasing of the oscillations lengths as well as in restriction of the disturbance amplitude variations.

The evanescent (near-step) modes contribution to the wave disturbances amplitude depends on the incident wave frequency. The magnitude of this contribution and the zone of its appreciable manifestation are significantly larger in front of the step than behind it. The frequency range of the evanescent eigenmode converges owing to the ice influence.

The ice cover also attenuates horizontal and vertical gradients of the wave current velocity near the step. The less the incoming wave period the greater is the effect. The wave current velocities decrease near the surface, the wave disturbances decay with depth, and near-step eigenmodes weakening of the wave currents formation are due to the ice cover as well.

\section{Flexural-gravity waves generated by moving pressure disturbances}

Squire et al. (1996) performed a detailed analysis of the ice flexural vibrations, caused by a straight moving load. However, it is interesting to consider a case of the nonlinear moving load. In particular, it may be an aircraft turning before landing or immediately after take-off or a helicopter, which generates atmospheric pressure disturbances of the vortex type under the rotating lobes and can induce ice vibrations when taking off, landing or flying at a small altitude. The ice vibrations also may be induced by atmospheric vorticity.

A mathematical model of the ice flexural vibrations, generated by a circling concentrated load (the centre of rotation is static) or by one moving rectilinearly at steady speed, was developed (Bukatov and Zharkov, 2001). Using the model, it was studied the dependence of amplitude-phase parameters of the generated waves on the ice flexural rigidity, load angular velocity and propagation speed of the load trajectory center. The simulation shows that wave disturbances are formed as wave eigenmodes sets. The model can provide estimations of the disturbances generated by an atmospheric vortex both of the natural and technical origin. When the load angular velocity is small, the model could describe disturbances induced by an aircraft flying along a curvilinear trajectory.

When the load trajectory center is static or propagates at low speed, a couple of spiral-form wave subsystems are generated for each wave eigenmode. From a certain value of the forward moving load speed, besides the spiral-form waves of a fixed eigenmode, a couple of flexural waves subsystems are induced due to the ice flexural rigidity. There is a critical value of the forward moving load speed above which the systems of the longitudinal and transverse ship waves are generated as well. The wave patterns of such a wave system are similar to those formed by a generator moving rectilinearly but they are non-symmetric relative to the center trajectory of the load.

There is a range of the forward moving load speed in which the phase patterns of the wave disturbances of a fixed wave eigenmode change qualitatively. At that the transverse gravity wave system can disappear, and the spiral-form wave arcs occur only inside some zone behind the load. If 
the load angular velocity does not exceed the critical value then starting with the certain speed of the moving load trajectory center the spiral-form waves of the corresponding eigenmode are not generated.

Within the moving load speed ranges when all the wave systems are generated, the contributions of the flexural, longitudinal and transverse gravity waves to the ice cover bending are comparable. The spiral-form waves contribution is insignificant

\section{Broken ice influence on propagation of waves of finite amplitude}

Using the infinite small wave assumption, many theoretical studies have been conducted to investigate the propagation of surface gravity waves under floating ice fields. These studies show that the ice field influence on the waves decreases with increasing wave period. The long-period waves of small amplitude travel under the ice without noticeable distortions. Murty and Polavarapu (1979) noted certain inconsistencies between current theoretical results concerning the ice effect on longperiod waves and real data. Detailed investigations of the floating ice role in the wave dynamics are still urgent.

To study the non-linear surface gravity waves in a basin with floating broken ice, a theoretical model has been proposed by Bukatov and Bukatov (1999), based on the multi-scale expansions approach (Nayfey, 1976). The uniformly appropriate asymptotic expansions up to values of third order of smallness for the basin surface elevation and velocity potential of moving water, formed when the periodic waves of finite amplitude propagate were obtained.

The dependence of the wave spatial profile on the parameters of the harmonic initial approximation, ice thickness and vertical acceleration non-linearity was studied. The disturbance parameters obtained taking and not taking into account the wave profile curvature in the velocity potential equation used for kinematic and dynamic boundary conditions at the basin surface in the non-linear approximation are compared.

It is shown that the floating broken ice may affect not only the short propagating periodic waves of finite amplitude but on the long ones as well. The effect is noticeable mainly in the wave phase shift and intensifies with time. The floating ice damps a propagating wave while non-linearity accelerates it. The shorter the initial wave harmonic the earlier the ice effect appears. Neglect of nonlinearity of the floes vertical acceleration in the dynamic boundary condition at the basin surface results in the wave phase lag and weak decreasing of the wave amplitude. These effects become apparent only on a large time scale. It decreases with wavelength increase of the linear approximation harmonic. On ice missing, the wave profile substitution into the velocity potential equation, used to obtain boundary conditions for the non-linear approximations leads to decrease of the frequency shift of the periodic propagating wave of finite amplitude. In addition the effect of curvature may appear both in the decrease and increase of the shift frequency. That depends on the wavelength of the harmonic in the linear approximation.

The ice effect on the mass transport due to the non-linear surface waves is analyzed. It is shown that the ice floes reduce the moving liquid particles speed and total mean mass transport. This effect becomes stronger with increasing of the initial harmonic wave steepness. The thicker the ice the less its Stokes drift velocity.

The asymptotic expansions up to the third order values of smallness for the basin surface elevation and liquid particles velocity potential in the wave disturbance formed by the non-linear coupling of propagating periodic waves of the first and second harmonics in the ice-covered homogeneous fluid of finite depth are obtained. The disturbance amplitude and phase structure dependence on the ice thickness, basin depth, and interacting harmonics parameters is investigated. The error due to the neglecting of the wave curvature in the velocity potential equation was estimated. On wave harmonics of finite amplitude interacting, the wave disturbance frequency was shown to depend on the initial amplitude of the main harmonic not only in the second but in the first approximations as well.

The ice effect may induce the interaction both between the short and long waves. When the letter is a case, it is noticeable mainly in the phase shift of the wave disturbances spatial distribution. 
The phase shift increases with time. The longer the wavelength of the initial wave harmonic the stronger is the ice influence not only on the phase velocity decrease but the disturbance amplitude as well. In the case of short waves, the appreciable ice effect manifests itself in the decrease not only of the phase velocity but also in the disturbance amplitude. The decrease in the amplitude is more significant when the initial phases of interacted harmonics are the same than when they are opposite.

The change in the phase of the initial second harmonic to the opposite one leads to deformation of the disturbances spatial distribution both quantitatively and qualitatively. At that the direction of phase variations caused by the ice floes does not change.

The second interacting harmonic contribution to the wave disturbances generation increases in the non-linear mass transport (Bukatov and Bukatov, 2001).

Neglecting the curvature in the expression for the wave disturbance velocity potential used in obtaining the boundary conditions for the non-linear approximations may result in appreciable errors in defining both the phase shift in the short-wave disturbances and the basin surface displacements from the non-disturbed level during the non-linear interaction of the wave harmonics.

\section{References.}

Bukatov A.E. and Bukatov AA. Propagation of Surface Waves of Finite Amplitude in a Basin with Floating Broken Ice // Int. J. Offshore and Polar Eng. - 1999. - V. 9, No. 3. - P. 161-166.

Bukatov A.E. and Bukatov A.A. Mass Transport under Non-linear Interaction between Surface Waves in the Basin with Floating Broken Ice. // Mor. Gidrofiz. Zhurn. - 2001 - No 2. - P. 310 .

Bukatov A.E. and Zav'yalov D.D. On Running of Flexible Gravity Waves over the Line of Contact of Two Starting Ice Plates of Different Depths // Mor. Gidrofiz. Zhurn. - 1998. - No 1. - P. 1117.

Bukatov A.E. and Zav'yalov D.D. Influence of a Shear and Inertia of Cross Sections Rotation upon Oscillations of Floating Ice Cover // Mor. Gidrofiz. Zhurn. - 2000. - No 6. - P. 28-35.

Bukatov A.E. and Zharkov V.V. Influence of Broken Ice on the Propagation of Surface Waves over a Bottom Shelf. // Izv. RAN. Mekh. Zhidk. i Gaza. - 1998. - No 6. - P. 106-115.

Bukatov A.E. and Zharkov V.V. The Floating Continuous Ice Cover's Flexural Oscillations When a Load is Moving Along a Complicated Trajectory // Int. J. Offshore and Polar Eng. - 2001. V. 11, No. 1. - P. 1-8.

Fox C. and Squire V.A. Refraction and Transmission Characteristics at the Edge of Shore Fast Sea Ice. // J. Geophys. Res. - 1990. - Vol. C95, No 7. - P. 11,629-11,639. Russian).

Kheisin D.Ye.. Dynamics of Ice Cover. Leningrad: Gidrometeoizdat, 1967. - 216 pp. (in

Krasil'nikov V.N. A Solution of Certain Boundary-contact. // Problems of Linear Hydrodynamics', Prikl. Mat. Mekh. - 1967. - V. 25, No 4. - P. 746-768.

Murty T.S. and Polavarapu R.J. Influence of an Ice Layer on the Propagation of Long Waves. // Marine Geodesy. - 1979. - Vol. 2, No 2. - P. 99-125.

Nayfey A.H. Perturbation methods. Moskva: Mir, 1976. - 455 pp (in Russian).

Newman J.N. Propagation of Water over an Infinite Step // J. Fluid Mech. - 1965. - V. 23, Pt 2. - P. 399-415.

Squire V.A., Hosking R.J., Kerr A.D. et al. Moving Loads on Ice Plates. Dordrecht: Kluwer, 1996. - 230 pp.

Wadhams P. The Seasonal Ice Zone. // The Geophysics of Sea Ice, Proc. NATO Adv. Study Inst. Air-Sea-Ice Interact. NewYork-London: Plenum Press, 1986. - Chap. 14. - P. 825-991. 